\section{Ocean pipes could help the Earth to cure itself}

SIR - We propose a way to stimulate the Earth's capacity to cure itself, as an emergency treatment for the pathology of global warming.

Measurements of the climate system show that the Earth is fast becoming a hotter planet than anything yet experienced by humans. Processes that would normally regulate climate are being driven to amplify warming. Such feedbacks, as well as the inertia of the Earth system - and that of our response make it doubtful that any of the wellintentioned technical or social schemes for carbon dieting will restore the status quo. What is needed is a fundamental cure.

The oceans, which cover more than $70 \%$ of the Earth's surface, are a promising place to seek a regulating influence. One approach would be to use free-floating or tethered vertical pipes to increase the mixing of nutrient-rich waters below the thermocline with the relatively barren waters at the ocean surface. (We acknowledge advice from Armand Neukermans on engineering aspects of the pipes.) Water pumped up pipes - say, 100 to 200 metres long, 10 metres in diameter and with a one-way flap valve at the lower end for pumping by wave movement would fertilize algae in the surface waters and encourage them to bloom. This would pump down carbon dioxide and produce dimethyl sulphide, the precursor of nuclei that form sunlight-reflecting clouds.

Such an approach may fail, perhaps on engineering or economic grounds. And the impact on ocean acidification will need to be taken into account.

But the stakes are so high that we put forward the general concept of using the Earth system's own energy for amelioration. The removal of 500 gigatonnes of carbon dioxide from the air by human endeavour is beyond our current technological capability. If we can't 'heal the planet' directly, we may be able to help the planet heal itself.

James E. Lovelock ${ }^{\star}$, Chris G. Rapley $\grave{\dagger}$

${ }^{\star}$ Green College, University of Oxford, Woodstock Road, Oxford OX2 6HG, UK $\uparrow$ Science Museum, Exhibition Road, South Kensington, London SW7 2DD , UK

\section{H-index: however ranked, citations need context}

SIR - The h-index (the number $n$ of a researcher's papers that have received at least $n$ citations) may paint a more objective picture of productivity than some metrics, as your News story 'Achievement index climbs the ranks' (Nature 448, 737; 2007) points out.
But for all such metrics, context is critical.

Many citations are used simply to flesh out a paper's introduction, having no real significance to the work. Citations are also sometimes made in a negative context, or to fraudulent or retracted publications. Other confounding factors include the practice of 'gratuitous authorship' and the so-called 'Matthew effect', whereby well-established researchers and projects are cited disproportionately more often than those that are less widely known. Finally, bibliometrics do not compensate for the well-known citation bias that favours review articles.

Michael C. Wendl

Washington University Medical School, 4444 Forest Park Boulevard,

Box 8501, St Louis,

Missouri 63108, USA

\section{$H$-index: age and sex make it unreliable}

SIR - The h-index seems to be breaking away from the bibliometric pack, in the race to become a favoured measure of scientific performance ('Achievement index climbs the ranks' Nature 448, 737; 2007). However, if the h-index is to become an assessment tool commonly used by university administrators and government bureaucrats, those using it should be aware of its pitfalls.

As noted in your News story, tallying how many papers a researcher publishes (their productivity) gives undue merit to those who publish many inconsequential papers. But at least for ecologists and evolutionary biologists, the h-index is highly correlated with productivity $(r=0.77$; see C. D. Kelly and M. D. Jennions Trends Ecol. Evol. 21, 167-170; 2006).

This is worrisome, because the h-index is easily misconstrued as an equitable measure of research quality. We offer two examples.

First, female ecologists and evolutionary biologists publish fewer papers than their male counterparts, and they have significantly lower h-indices. Should administrators therefore conclude that men are better researchers? No. The gender difference vanishes if we control for productivity. It seems unlikely that this phenomenon is restricted to ecology and evolution.

Second, the h-index increases with age and using the ratio of the two can be problematic. Therefore, reliably comparing the performance of younger researchers with older ones is difficult.

Clint D. Kelly, Michael D. Jennions

School of Botany and Zoology,

Australian National University,

Canberra, ACT 0200, Australia

\section{Conservationists could slip up in oil-palm enterprise}

SIR - In a novel 'farming with the enemy' approach, Lian Pin Koh and David S. Wilcove (Nature 448, 993-994; 2007) suggest that non-governmental organizations (NGOs) should cash in on the lucrative oil-palm industry and buy small tracts of existing plantations to generate revenue for nature reserves. Such a scheme has many potential complications and ramifications.

According to Koh and Wilcove's figures, an NGO would require $\$ 62.5$ million to purchase 5,000 hectares of mature oil palm; the same sum of money would buy 11,000 hectares of forested land outright. It would take six years to recoup this investment through revenues from the plantation. Only then could forested land be bought, at 1,800 hectares a year, reaching a total of 11,000 hectares 12 years after the oil-palm purchase. Given the high rates of deforestation in southeast Asia, it seems more prudent to simply acquire forests now.

NGOs may spread themselves too thin if they engage in a large business that will divert considerable manpower, time and expertise away from threatened-species recovery programmes and public outreach. In addition, acquisition of oil-palm plantations by NGOs may exacerbate current rates of land conversion, by reducing the number of hectares available for other private plantation owners. And we fail to see how the proposed scheme will prompt companies to commit to good management practices, such as those advocated by the Roundtable on Sustainable Palm Oil (www.rspo.org). Instead, oil-palm monoculture could be legitimized as 'green' by an NGO's association with companies that are required to do nothing more than assist in starting up their plantations.

We propose instead that NGOs actively engage oil-palm companies to fund reserves, in return for environmentally friendly accreditation and help in implementing guidelines for sustainability.

Although conservationists must find creative ways to raise funds sustainably, doing so through an industry that has negative impacts on biodiversity may ultimately be counterproductive. Reuben Clements, Mary Rose C. Posa Department of Biological Sciences, National University of Singapore, 14 Science Drive 4, Singapore 117543, Republic of Singapore

\footnotetext{
Contributions to Correspondence may be submitted to correspondence@nature.com. They should be no longer than $\mathbf{3 0 0}$ words. Published contributions are edited. We welcome comments at Nautilus (http://blogs.nature.com/nautilus).
} 